\title{
In-situ Observation of Damage Structure in Fe-Cr Alloys by means of HVEM-ion Accelerator Facility
}

\author{
S. Ohnuki, N. Hashimot H. Seto, N. Yamaguchi, H. Kinoshita and S. Watanabe \\ Department of Materials Science and Engineering, Hokkaido University, \\ N-13 W-8, Kita-ku, Sapporo 060-8628, Japan
}

Hokkaido University has installed multi-beam irradiation facility combining with atomic resolution high voltage electron microscope and ion-accelerators. By using the facility several groups have used for in-situ observation of damage structure in nuclear reactor materials [1] and systhesization of non-stoichiometric phases [2]. At this time an example of in-situ observation for damage development in fusion and fission reactor materials will be introduced during an electron-helium ion irradiation.

Ferritic/martensitic steels are candidates for fusion reactor, however, there are main materials issues such as irradiation embrittlement and elevation in ductile-brittle transition temperature. Now days, migration energy of point defects influence evolution of irradiation-induced dislocation loops, and hydrogen and/or helium created by nuclear transmutation reaction are becoming important terms in "Multi-scale modeling" applying for solving such macroscopic materials behavior.

In order to investigate the effect of helium on migration energy of vacancies or interstitials in $\mathrm{Fe}-\mathrm{Cr}$ model alloys, two types of irradiations, electron single irradiation and electron-helium dual irradiation and their in situ observations were performed at $300-500{ }^{\circ} \mathrm{C}$. The acceleration voltage of electron in JEOL ARHVEM was $1250 \mathrm{kV}$, and the voltage of He ion was $100 \mathrm{kV}$. The damage rate was $10 \times 10-4 \mathrm{dpa} / \mathrm{s}$, and the injection rate was $10 \mathrm{He} \mathrm{ppm} / \mathrm{dpa}$.

At the beginning of the electron-irradiation interstitial-type dislocation loops were nucleated and then grew on $<001>$ and $<111>$, as shown in Fig. 1. In the case of dual-beam irradiation, the loops were nucleated with much higher number density, and the grown with continuing irradiation, as shown in Fig. 2. By using simple method based on Kiritani and Yoshida [3], the migration energy of interstitials was evaluated as $0.2 \mathrm{eV}$ in both types of irradiations, and that of vacancies was evaluated as $0.95 \mathrm{eV}$ in electron-irradiation and $1.5 \mathrm{eV}$ in dual beam irradiation, where the difference of two energies, $0.5 \mathrm{eV}$, could be assumed to be net binding energy of vacancy and helium atom. These results are reasonable comparing to the results from other materials, as shown in Table 1.

References

[1] K. Oka, S. Ohnuki, S. Yamashita, N. Akasaka, H. Tanigawa, Mater. Trans., 48 (2007)25632566

[2] S. Watanabe, Mater. Sci. Forum, $561-565$ (2007) 2021

[3] M. Kiritani et al., J. Phys. Japan, 38 (1975) 


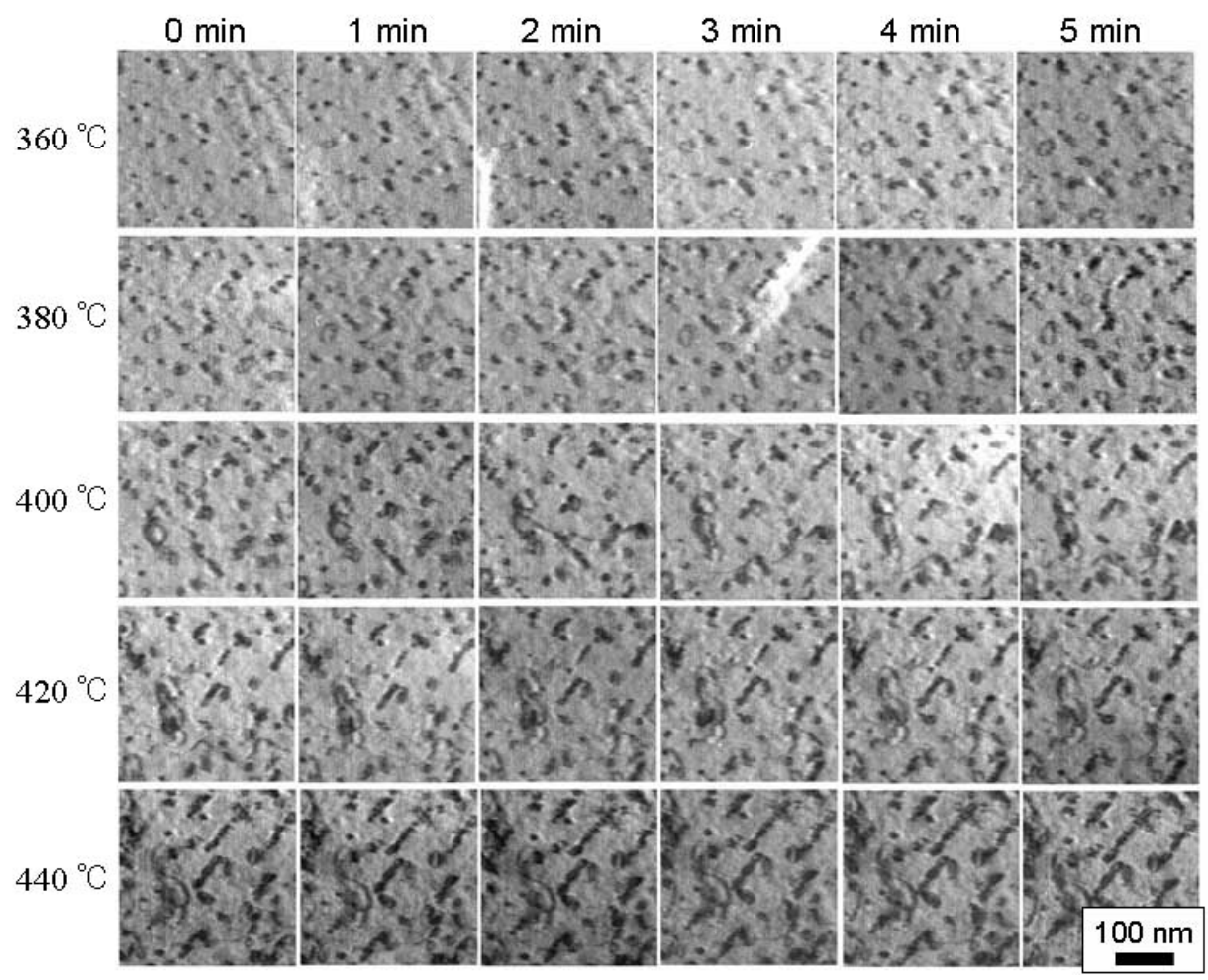

FIG. 1. Continuous growth of dislocation loops during electron-irradiation at different temperature

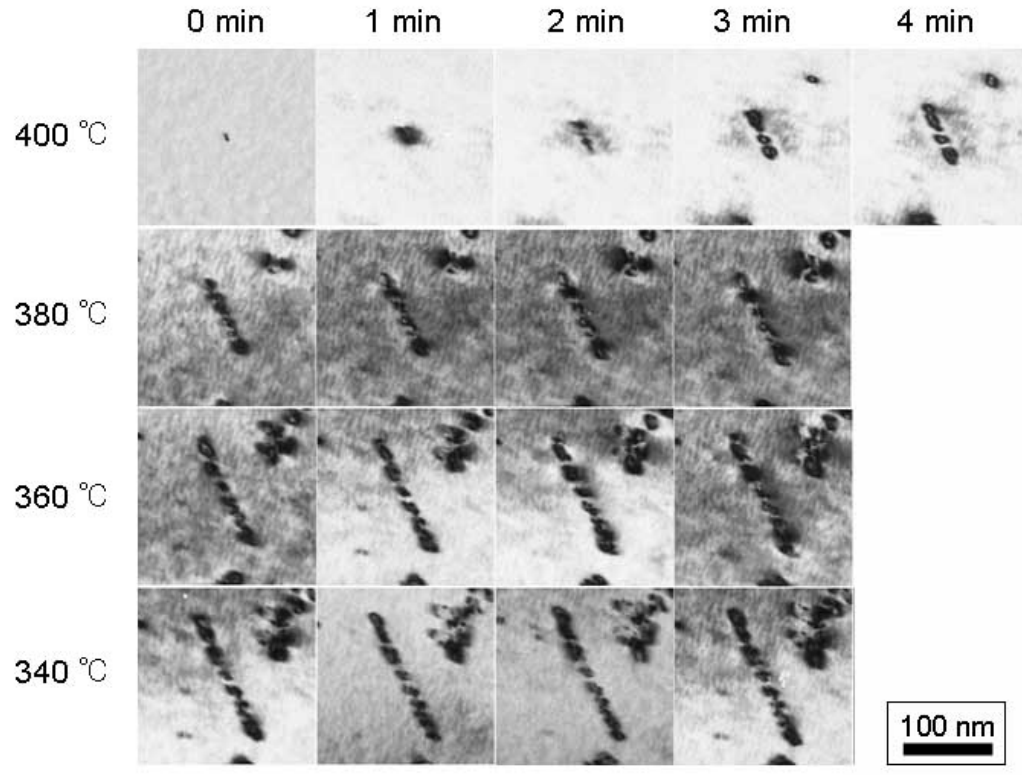

FIG. 2. Continuous growth of dislocation loops during electron-He ion irradiation at different temperature

TABLE 1. Net migration energies from electron-irradiation experiments

\begin{tabular}{|c|c||c||c|}
\hline Materials & Vacancy migration energy $(\mathrm{eV})$ & Interstitial migration energy $(\mathrm{eV})$ & \\
\hline Fe-Ni-Cr without He & 1.04 & 0.9 & Hidaka et al. \\
\hline \hline $20 \mathrm{appmHe} / \mathrm{dpa}$ & 1.19 & 0.9 & Hidaka et al. \\
\hline $70 \mathrm{appmHe} / \mathrm{dpa}$ & 1.53 & - & Hidaka et al. \\
\hline \hline $\mathrm{Fe}$ & $0.7-1.0$ & $0.2-0.3$ & Kiritani, Yoshida, \\
\hline
\end{tabular}

